\title{
Effect of LLDPE on Aging Resistance and Thermal, Mechanical, Morphological Properties of UHMWPE/LLDPE Blends
}

\author{
Caroline Martins dos Santos ${ }^{a}$, Bruna Cristina da Silva ${ }^{a}$ Eduardo Henrique Backes, \\ Larissa Stieven Montagna ${ }^{a}$ Luiz Antonio Pessan ${ }^{b}$, Fabio Roberto Passador ${ }^{a}$ *(D) \\ aUniversidade Federal de São Paulo - UNIFESP, São José dos Campos, SP, Brasil \\ ${ }^{b}$ Universidade Federal de São Carlos - UFSCar, São Carlos, SP, Brasil
}

Received: May 02, 2018; Accepted: July 17, 2018

\begin{abstract}
Blends of ultra-high molecular weight polyethylene (UHMWPE) and different contents $(0,10$, 20 and $30 \mathrm{wt} \%$ ) of linear low-density polyethylene (LLDPE) with and without maleic anhydridegrafted LLDPE (LLDPE-g-MA) were prepared by melt blending and aging resistance, thermal and mechanical properties were evaluated. The degree of crystallinity increases with the content of LLDPE in the blends. On the other hand, the addition of compatibilizer agent modifies the crystallinity and the crystallite size. Non-compatibilized blends have excellent impact resistance properties and the addition of LLDPE-g-MA aids processing but decrease the impact resistance of the blends. Thermal and mechanical properties were greatly affected by thermal and water aging. The thermal aging leads to an increase in the degree of crystallinity and consequent a decrease in impact resistance.
\end{abstract}

Keywords: $U H M W P E, L L D P E$, polymer blends, aging resistance.

\section{Introduction}

Ultra-high molecular weight polyethylene (UHMWPE) is a thermoplastic polymer that has extremely high molecular weight and offers high impact resistance and toughness, elevated wear strength and fatigue resistance, low coefficient of friction and high environmental stress cracking resistance ${ }^{1-4}$. Because of its mechanical properties, UHMWPE is widely used in automotive and aircraft ballistic protection, body armor, fishing nets, hip/knee implants, and climbing rope $\mathrm{e}^{5-8}$. Even above its melting temperature, UHMWPE still possesses a high melt viscosity, and cannot be processed through the mainstream thermoplastic processing techniques like extrusion and injection molding, the exception of compression molding and ram extrusion ${ }^{6}$ which largely restricts its efficiency of mass production. However, the processability of UHMWPE can be improved by blending with conventional polyolefins ${ }^{4,6}$. The blending of such similar chemical nature of polyethylenes may lead to a synergistic effect in terms of enhancement in impact toughness and other mechanical properties ${ }^{9}$.

Due to the poor flow of UHMWPE, several techniques are used to prepare UHMWPE blends, such as melt mixing, coarse powder blending followed by compression molding solvent blending and shear controlled orientation injection molding ${ }^{4,10-11}$. The incorporation of UHMWPE in other polyethylenes using the solvent blending technique provides good homogeneity, however, is not suitable for large-scale production, since it requires large quantities of solvent and the protocols of mixing affect the final morphology of the blend.

*e-mail: fabiopassador@gmail.com
On the other hand, UHMWPE/high-density polyethylene (HDPE) and UHMWPE/low-density polyethylene (LDPE) blends can be prepared by melt mixing using conventional extruder but the incomplete melting of UHMWPE results in a dispersion of particles which affect the properties of the blends ${ }^{4,11}$.

Among the polyethylenes used to modify the UHMWPE, HDPE has been used in many fields. UHMWPE can provide many excellent properties on HDPE materials, such as outstanding mechanical properties, low friction, and low wear rate as well excellent fatigue resistance ${ }^{12}$. However, UHMWPE is still in a rubbery state even above its melting temperature and the UHMWPE particles will only suspend in the melted HDPE matrixes ${ }^{12}$. Instead, there is a distinct interface between HDPE matrix and dispersed UHMWPE particle, which may result in phase separation and poor performance of the blend ${ }^{13}$. Boscolleto et al. ${ }^{14}$ reported that UHMWPE was only partially dissolved in HDPE/UHMWPE blends during melt blending. In this case, the UHMWPE component cannot be well mixed with the HDPE matrixes. The major reason for that is low chain entanglements across the phase interfaces between HDPE and UHMWPE, which are caused by extremely slow chain diffusion of UHMWPE. Kyu and Vadhar ${ }^{15}$ have reported that cocrystallization takes place in the blends of UHMWPE/HDPE blends. However, separate crystals are formed in UHMWPE/LDPE blends.

In this way, other processes have been studied. Chen et al. ${ }^{11}$ prepared HDPE/UHMWPE blends via solid-state shear milling and compared with the melt mixing blends and this process showed improvements in the strength and elongation at break of HDPE/UHMWPE blends when compared to 
melt mixing blends. This same process was used for LDPE/ UHMWPE blends and the results were also very satisfactory ${ }^{4}$. Thus, an effective way to prepare UHMWPE/polyethylene blends is the use of the intensive mixer/homogenizer, which melts the polymer due to the high friction between the particles producing a homogeneous blend.

There are only a few reports regarding the preparation of UHMDPE/linear low-density polyethylene (LLDPE) blends. Chen et al. ${ }^{16}$ prepared LLDPE/UHMWPE blends with 10, 20, 30 and $40 \mathrm{wt} \%$ of UHMWPE by melt blending and reported inhomogeneity and phase separation in the system. The incorporation of a compatibilizer agent into the blend can promote interfacial adhesion and bonding of immiscible phases, through stabilization of phase morphology against coalescence effects, which results in a reduction of dispersed phase particle size. Several types of compatibilizer agents can be added to the polymer blend. The grafting of maleic anhydride to the polyolefin backbone significantly increases the polarity and, thus, can improve their surface hydrophilicity. The use of maleic anhydride (MA) as compatibilizer agent for polymer blends can promote a controlled morphology and enhanced mechanical properties ${ }^{17-18}$.

In this present study, UHMWPE/LLDPE blends with different contents of LLDPE were prepared by mechanical melt mixing using maleic anhydride functionalized linear low-density polyethylene (LLDPE-g-MA) as compatibilizer agent and the structural, thermal and mechanical properties were correlated. The UHMWPE and LLDPE were chosen because they have a similar chemical structure and different melt index. The compatibilizer agent was chosen because it has the same melt index of the LLDPE and it is expected that the compatibilizer is miscible with the components of the polymer matrix. Moreover, this blend is of great importance for the production of individual protective equipment, such as protective helmets and ballistic shields, which are usually mixed with polar fillers, so the study of the addition of the compatibilizer agent and the effect on the polymer blends may contribute to studies with polar fillers.

\section{Experimental Procedure}

\subsection{Materials}

The ultra-high molecular weight polyethylene, UHMWPE, (UTEC 6540) with an intrinsic viscosity of $28 \mathrm{dL} / \mathrm{g}$ (ASTM D 4020) and linear low-density polyethylene, LLDPE, (IC 32) with a melt index of $29 \mathrm{~g} / 10 \mathrm{~min}\left(190^{\circ} \mathrm{C} / 2.16 \mathrm{~kg}\right)$ were supplied by Braskem, Brazil.

The maleic anhydride-grafted linear low-density polyethylene, LLDPE-g-MA, (Polybond ${ }^{\circledR} 3109$ ) was purchased from Crompton Corporation. The LLDPE and LLDPE-g-MA were chosen because they have the same melt index (MI = $\left.30 \mathrm{~g} / 10 \mathrm{~min}\left(190^{\circ} \mathrm{C} / 2.16 \mathrm{~kg}\right)\right)$.

\subsection{Melt processing}

UHMWPE was mixed together with LLDPE composition of $0,10,20$ and $30 \mathrm{wt} \%$ respectively, using a high-speed mixer (Drais mixer produced by MH Equipamentos, Brazil, model $\mathrm{MH} 50 \mathrm{H}$ ) rotating at $3000 \mathrm{rpm}$ and mixing chamber with a capacity of $70 \mathrm{~g}$ of material. The mixing, melting and homogenization of the blends occur due to the high friction generated between the rotor and the material. The mixing temperature was monitored using a thermocouple and reached $200^{\circ} \mathrm{C}$ in 40 seconds mixing. After 1 min of mixing, the homogenized blends were collected and pressed into $3.2 \mathrm{~mm}$ thick plates in a hydropneumatic press $(\mathrm{MH}$ Equipamentos, Brazil, model PR8HP) at $200^{\circ} \mathrm{C}$ with a pressure of 5 bar for $3 \mathrm{~min}$. Standardized specimens for the impact test were prepared using a pneumatic hollow die punch machine (CEAST/Instron). These UHMWPE/ LLDPE blends were denoted as UL.

UHMWPE/LLDPE blends with the addition of LLDPEg-MA were prepared using the same mixing methodology. UHMWPE/LLDPE/LLDPE-g-MA blends with 10, 20 and 30 $\mathrm{wt} \%$ of LLDPE and blending ratio of 2: 1 (LLDPE/LLDPEg-MA) were prepared and denoted as ULL. The details of the investigated blends composition and their designation are presented in Table 1.

\subsection{Characterization of the blends}

The differential scanning calorimetry (DSC) analysis was performed using TA Instruments QS100 equipment, under $\mathrm{N}_{2}$ atmosphere. The measurements of neat UHMWPE, neat LLDPE, and UHMWPE/LLDPE blends were performed according to the following procedures: samples were heated to $200^{\circ} \mathrm{C}$ at $10^{\circ} \mathrm{C} \cdot \mathrm{min}^{-1}$ and kept at this temperature for $5 \mathrm{~min}$ to erase any previous thermal history, then cooled to $40^{\circ} \mathrm{C}$ at $10^{\circ} \mathrm{C} \cdot \mathrm{min}^{-1}$ to determine the crystallization temperature $\left(\mathrm{T}_{\mathrm{c}}\right)$. The melting point $\left(\mathrm{T}_{\mathrm{m}}\right)$ was taken at the melting endothermic peak of the second heating cycle after erasing the thermal

Table 1. Composition and designation of UHMWPE/LLDPE and UHMWPE/LLDPE/LLDPE-g-MA blends.

\begin{tabular}{lccc}
\hline $\begin{array}{l}\text { Blends } \\
\text { Composition }\end{array}$ & UHMWPE(wt\%) & $\begin{array}{c}\text { LLDPE } \\
(\mathrm{wt} \%)\end{array}$ & $\begin{array}{c}\text { LLDPE- } \\
\text { g-MA } \\
(\mathrm{wt} \%)\end{array}$ \\
\hline $\begin{array}{l}\text { UHMWPE } \\
(100)\end{array}$ & 100 & --- & --- \\
LLDPE (100) & --- & 100 & --- \\
UL10 & 90 & 10 & --- \\
UL20 & 80 & 20 & --- \\
UL30 & 70 & 30 & --- \\
ULL10 & 85 & 10 & 5 \\
ULL20 & 70 & 20 & 10 \\
ULL30 & 55 & 30 & 15 \\
\hline
\end{tabular}


history. The degree of crystallinity (Xc) of the blends was determined from the Eq. 1.

$$
X_{c}(\%)=\left(\Delta H_{m} / \Delta H_{m}^{0} \times \phi_{\text {blend }}\right) .100,
$$

where $\Delta \mathrm{H}_{\mathrm{m}}$ is the enthalpy of fusion directly obtained by DSC, $\Delta H_{m}^{0}$, the enthalpy of fusion of $100 \%$ crystalline polymer, was taken as $286.2 \mathrm{~J} / \mathrm{g}$ for UHMW-PE and 140.6 $\mathrm{J} / \mathrm{g}$ for LLDPE and $\varphi$ blend is the volume fraction of the components in the blend.

The thermogravimetric analysis (TGA) of the compositions was performed using a Q50 TA Instruments equipment, from room temperature to $800^{\circ} \mathrm{C}$ at a rate of $20^{\circ} \mathrm{C} / \mathrm{min}$, under $\mathrm{N} 2$ atmosphere.

The wide-angle X-ray diffraction (WAXD) was conducted using a Rigaku Ultima IV (PANalytical, model X'pert Powder) diffractometer, with $\mathrm{Cu}-\mathrm{K} \alpha$ radiation $(\lambda=1.54056 \AA)$, operating at $40 \mathrm{kV}$ and $30 \mathrm{~mA}$ at a scan rate of $0.02 \% \mathrm{~s}$ in a range of $2 \theta$ from 10 to $30^{\circ}$. The diffraction patterns data were used to calculate the degrees of crystallinity and the crystallite sizes. Subsequently, through mathematical deconvolution of the peaks in WAXD profiles, the overall crystallinity Xc was calculated by Eq. 2 which correlates the sum of the area of all peaks associated with crystalline area divided by the sum of crystalline and amorphous peaks.

$$
X_{c}=\frac{\sum A_{\text {cryst }}}{\sum A_{\text {cryst }}+\sum A_{\text {amorp }}}
$$

where Acryst and Aamorp are the fitted areas of crystalline and amorphous peaks, respectively. The samples used were prepared by compression molding with the thickness of $3.2 \mathrm{~mm}$.

The apparent crystalline size was determined according to Scherrer's equation (Eq. 3).

$$
D_{(h k l)}=\frac{K \lambda}{\beta \cos \theta}
$$

where $\beta$ is the half-width of the diffraction peak in radians, $\mathrm{K}$ is equal to $0.9, \theta$ is the Bragg angle and $\lambda$ is the wavelength of the X-rays. The values of $D_{(h k l)}$ for (110) reflection were calculated.

The fracture surface morphology of the blends was analyzed by scanning electron microscopy (SEM). The samples were cryogenically fractured and covered with a thin layer of gold. The fracture surface was observed in a scanning electron microscope FEI Inspect S50, operating at $15 \mathrm{keV}$.

Impact tests were performed on a CEAST/Intron Charpy impact testing machine (model 950). The test method adopted was carried out according to ASTM D256-78 method B. Five test specimens of each composition were notched using a manual notched machine (CEAST/Instron). Impact loading was done with a $5.5 \mathrm{~J}$ hammer.

\subsection{Aging resistance}

The regulatory standards of the Brazilian Army (NEB/T E-316) and the National Institute of Justice (NIJ Standard 0101.04 - USA) for ballistic protection specify that for armor approval for personal use, samples must be aged in an air circulation oven and in water at $70^{\circ} \mathrm{C}$ for 72 hours, seeking to submit the material to the practical limits of application. However, this work intends to submit the samples under more severe conditions, in order to know the thermal resistance limit of the blends.

The aging resistance was analyzed by two methods: samples aged in water at $80^{\circ} \mathrm{C}$ for 7 days (AW) and samples aged in an oven at $110^{\circ} \mathrm{C}$ for 7 days (AO). For the first method the samples were placed in a distilled water circulation (Nova instruments), the water absorption (WA) of the samples was determined from the Eq. 4.

$$
W A(\%)=\left(m_{f}-m_{i} / m_{i}\right) .100
$$

where $m_{i}$ is initial mass and $m_{f}$ is the mass after aging. In the second method, the samples were placed in an oven with air circulation (Sterilifer, model SX CR/200). After aging the samples were characterized using differential scanning calorimetry (DSC), Charpy impact tests and Fourier transform infrared spectroscopy (FTIR). For the DSC test, the samples were heated to $200^{\circ} \mathrm{C}$ at $10^{\circ} \mathrm{C} \cdot \mathrm{min}^{-1}$ and only the first heating was evaluated to verify the influence of aging on the degree of crystallinity. Impact tests were performed on a CEAST/ Intron Charpy impact testing machine (notched specimens and 5.5J hammer). FTIR was performed using a Shimadzu spectrophotometer (model IR Affinity ${ }^{-1}$ ) the samples were mixed with potassium bromide $(\mathrm{KBr})$ powder and pressed with $2 \mathrm{~mm}$ disk thickness. The measurement range was from 400 to $4000 \mathrm{~cm}^{-1}$.

\section{Results and Discussion}

Figures 1 and 2 show the DSC thermograms for neat UHMWPE, neat LLDPE and the blends with different contents of LLDPE. Table 2 summarizes the values of melting temperature $\left(\mathrm{T}_{\mathrm{m} 1}\right.$ and $\left.\mathrm{T}_{\mathrm{m} 2}\right)$ obtained on the first and second heating scans and the values of crystallization temperature $\left(\mathrm{T}_{\mathrm{c}}\right)$ obtained during the cooling scan and the values of crystallinity degree for the first and second scan $\left(\mathrm{Xc}_{1}\right.$ and $\left.\mathrm{Xc}_{2}\right)$.

The neat LLDPE (Figure 1c) shows a bimodal and relatively broad peak due to its branching. The bimodal response is composed of a low temperature shoulder and a high temperature peak ${ }^{16}$. In Figure 1 b, UHMWPE exhibited higher crystallization peak (Tc) than LLDPE, but a lower crystallinity (Xc) (shown in Table 2). After the addition of LLDPE to the UHMWPE, there is a shift and change in melting point, which can be attributed to the van der Waals 


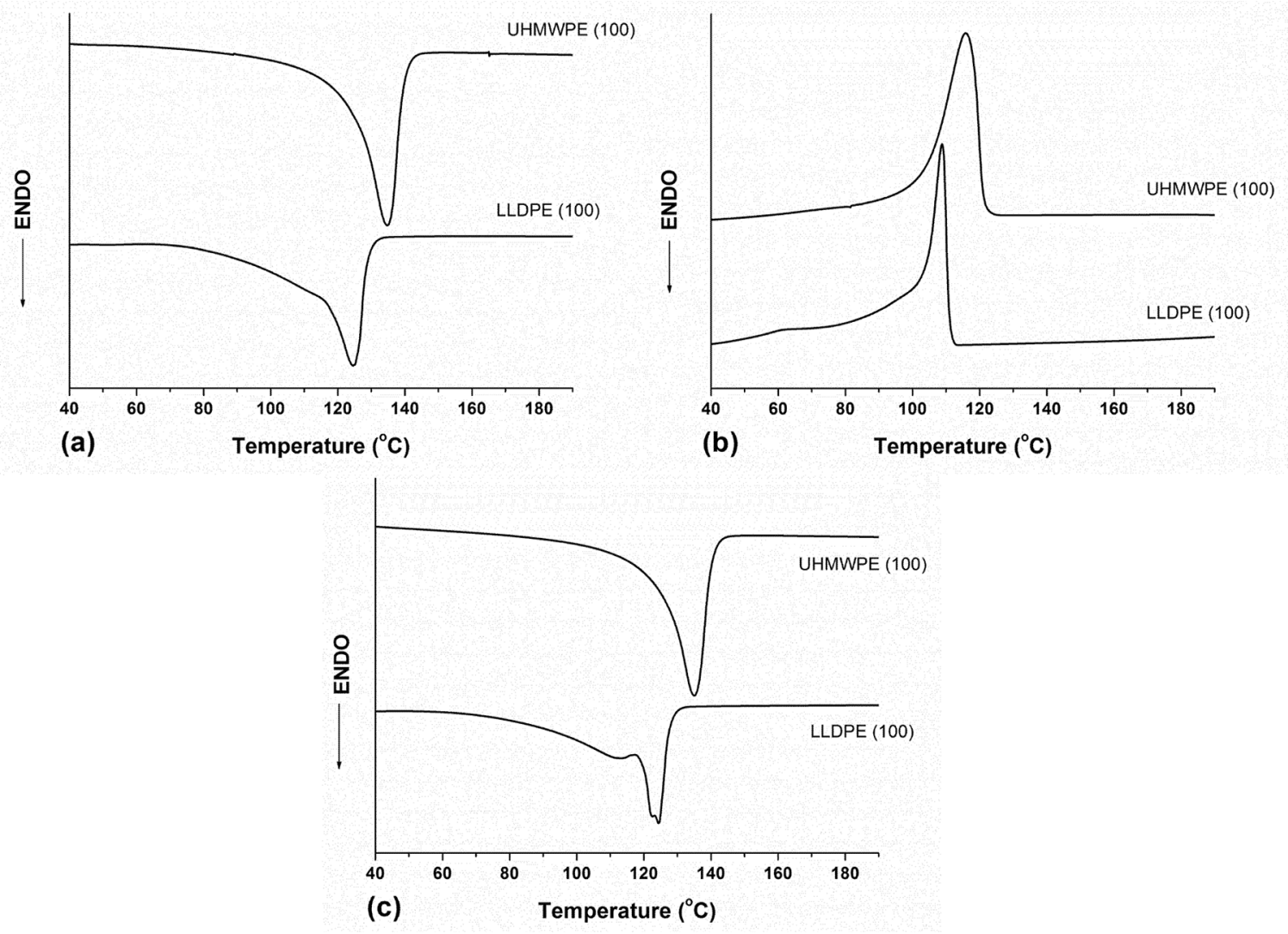

Figure 1. DSC thermograms of UHMWPE and LLDPE: (a) first heating, (b) cooling and (c) second heating.
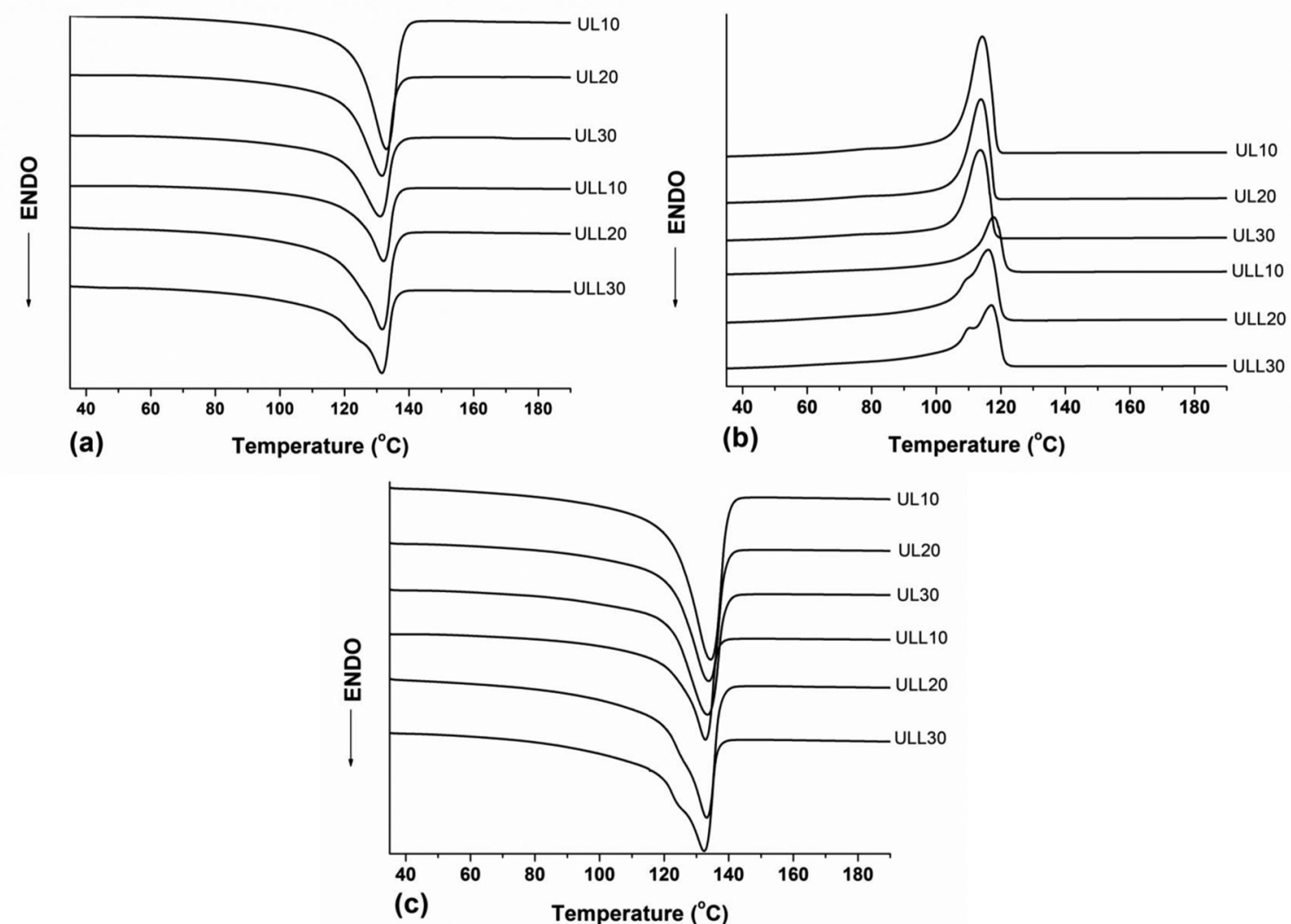

Figure 2. DSC thermograms of UHMWPE/LLDPE blends and UHMWPE/LLDPE/LLDPE-g-MA blends: (a) first heating, (b) cooling and (c) second heating. 
Table 2. Values of $T m$ and $X_{c}$ obtained during heating scans and $T_{c}$ obtained during cooling scan, and values of onset temperature $\left(T_{0}\right)$ obtained by TGA.

\begin{tabular}{lcccccc}
\hline & $\mathrm{Tm}_{1}\left({ }^{\circ} \mathrm{C}\right)$ & $\mathrm{Xc}_{1}(\%)$ & $\mathrm{T}_{\mathrm{c}}\left({ }^{\circ} \mathrm{C}\right)$ & $\mathrm{Tm}_{2}\left({ }^{\circ} \mathrm{C}\right)$ & $\mathrm{Xc}_{2}(\%)$ & $\mathrm{T}_{0}\left({ }^{\circ} \mathrm{C}\right)$ \\
\hline UHMWPE (100) & 135 & 39.6 & 116 & 135 & 42.7 & 472.1 \\
LLDPE (100) & 125 & 60.9 & 109 & 124 & 61.2 & 448.0 \\
UL10 & 133 & 49.1 & 114 & 134 & 52.1 & 464.1 \\
UL20 & 132 & 54.6 & 114 & 134 & 56.7 & 462.0 \\
UL30 & 132 & 48.4 & 113 & 136 & 59.5 & 461.5 \\
ULL10 & 133 & 47.0 & 117 & 133 & 50.6 & 462.3 \\
ULL20 & 132 & 52.0 & 116 & 133 & 56.1 & 460.5 \\
ULL30 & 132 & 58.6 & 117 & 132 & 62.8 & 460.9 \\
\hline
\end{tabular}

force between the two polymers ${ }^{21}$. For all blends prepared without addition of compatibilizer agent (UL) it was observed only a single crystallization temperature and a single melting temperature peaks (Figure 2 b) which becomes wider compared to those of the neat components indicating the existence of only one type of crystal species. These results may be an indicator of the miscibility of the system and that co-crystallization took place in the UHMWPE/LLDPE blend. Crystallization temperature (Tc) and melting temperature (Tm) remained broadly unaffected (Table 2 ). It is noticed that increasing the LLDPE content there is a slight increment in the degree of crystallinity of the blends, however, the degree of crystallinity is lower than LLDPE. This reduction may be attributed to the mobility restriction of LLDPE chains to diffuse into UHMWPE high viscous matrix ${ }^{9}$.

On the other hand, the addition of compatibilizer agent in these systems (ULL) shows that increasing LLDPE content in the composition (ULL20 and ULL30) leads to a lower temperature shoulder peak and a higher temperature sharp peak in the crystallization curve (Figure $2 \mathrm{~b}$ ), and they respectively correspond to the LLDPE component and UHMWPE component. The difference between the behavior of UHMWPE and LLDPE is a result of the branching since LLDPE has short chain branching while UHMWPE has an almost linear structure. According to Chen and co-workers ${ }^{16}$, the high temperature peak is attributed to the co-crystallization of linear fractions of LLDPE and UHMWPE, whereas, the broad shoulder at lower temperature represents melting of the lamellae formed by branched LLDPE chains. The appearance of two peaks could indicate a poor mixing or separate crystal formation. It is noteworthy that these compositions exhibit the large content of LLDPE since it was used the proportion of 2:1 (LLDPE: LLDPE-g-MA). Thus, the branching presents in the LLDPE-g-MA may also be contributing to the appearance of this shoulder which is more evident/apparent for larger contents of LLDPE in the blend. The degree of crystallinity of the ULL blends increased with the content of LLDPE and LLDPE-g-MA, indicating that the higher content of these components facilitates the diffusion and enhance the mobility of the UHMWPE chains. The higher content of LLDPE in the blends aids the processing since LLDPE has high chain mobility, which allows greater mixing capacity and increases in the degree of crystallinity of the blends compared to neat UHMWPE.

Figure 3 shows the TGA curves of neat materials, UHMWPE/LLDPE blends, and UHMWPE/LLDPE/LLDPEg-MA blends. The results are summarized in Table 2. The onset temperature $\left(\mathrm{T}_{\mathrm{O}}\right)$ of UHMWPE/LLDPE blends showed intermediate values between the individual polymers used. Increasing the content of LLDPE occurs a slight decrease in the values of onset temperature. This fact was already expected because the LLDPE has a lower onset temperature compared to UHMWPE. The addition of compatibilizer in the blends lead to a slight decrease in the onset temperature since the onset of decomposition of the maleic anhydride occurs at lower temperatures than for the polyethylene. This fact can be confirmed by analyzing the results of the compatibilized blends (ULL) with a high content of LLDPE. In all cases it was used a ratio 2:1 (LLDPE: LLDPE-g-MA), i.e., when increasing the LLDPE content in the blend we have double the content of compatibilizer agent and it results in a decrease of onset temperature. Similar results were obtained for polyethylenes blend-based organoclay nanocomposites compatibilized with LLDPE-g-MA ${ }^{19}$.

The X-ray scattering experiments were performed to obtain information about crystallinity and crystallite size of the systems studied. The X-ray diffraction results are shown in Figure 4. It can be seen that all samples have two welldefined crystallographic plans, (lll 110$)$ and (2 $\left.\begin{array}{lll}2 & 0\end{array}\right)$. There are similar crystal structures for both neat UHMWPE and LLDPE, i.e. orthorhombic lattice, which is retained after the blending procedure ${ }^{20,21}$.

One simple approach to estimate the apparent degree of crystallinity from the WAXD experiment is to compute the integrated intensities of the pattern associated with the crystalline structures and the amorphous halo. Table 3 shows the values of crystalline parameters for UHMWPE, LLDPE, and UHMWPE/LLDPE blends. As it is known that the crystallinity is dependent on the molecular structure of the polymer chains. LLDPE has a higher content of short branched-chain segments compared to UHMWPE. However, the very high molecular weight of UHMWPE hinders 

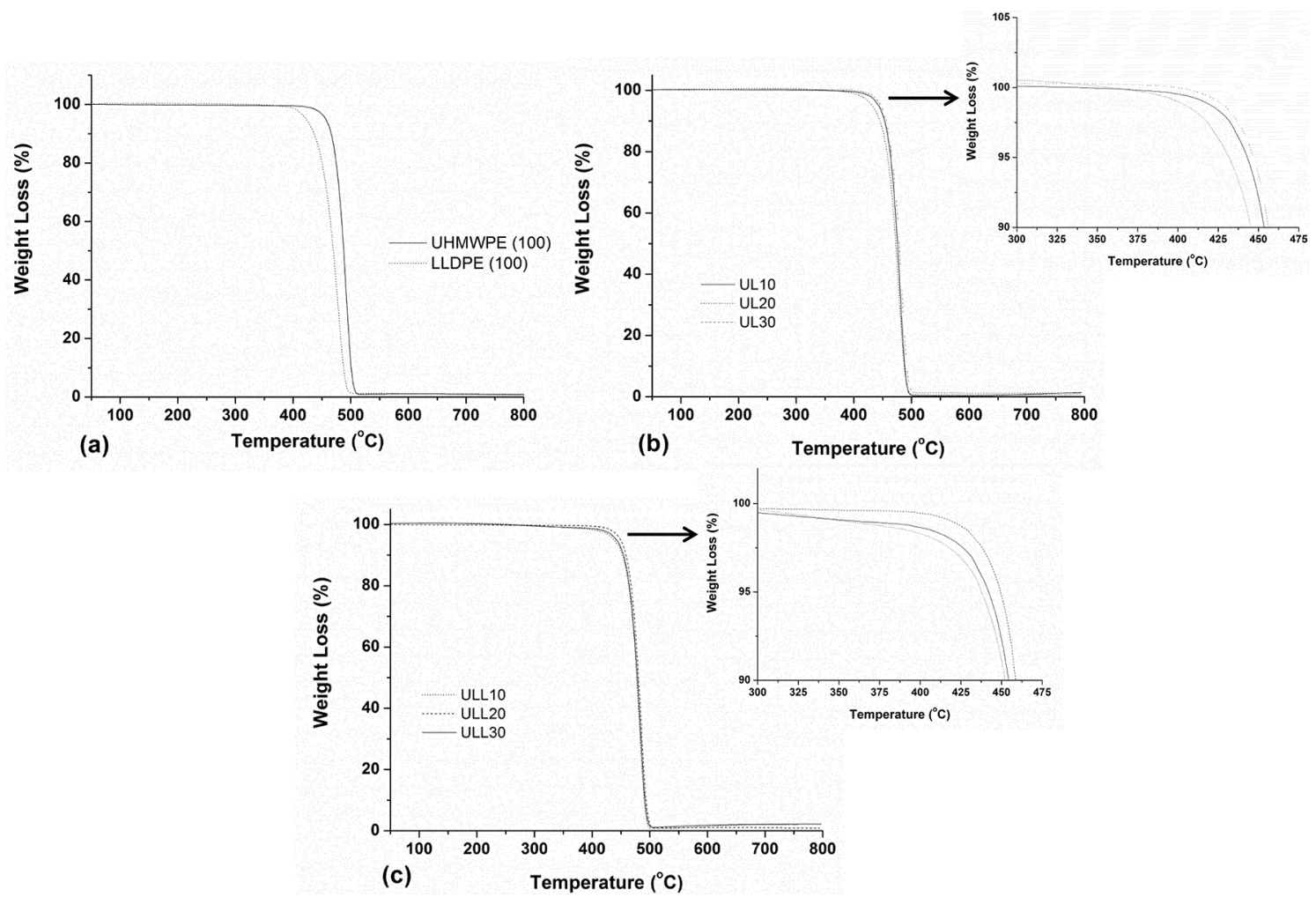

Figure 3. TGA analysis (a) UHMWPE and LLDPE, (b) UHMWPE/LLDPE blends and (c) UHMWPE/LLDPE/LLDPE-g-MA blends.
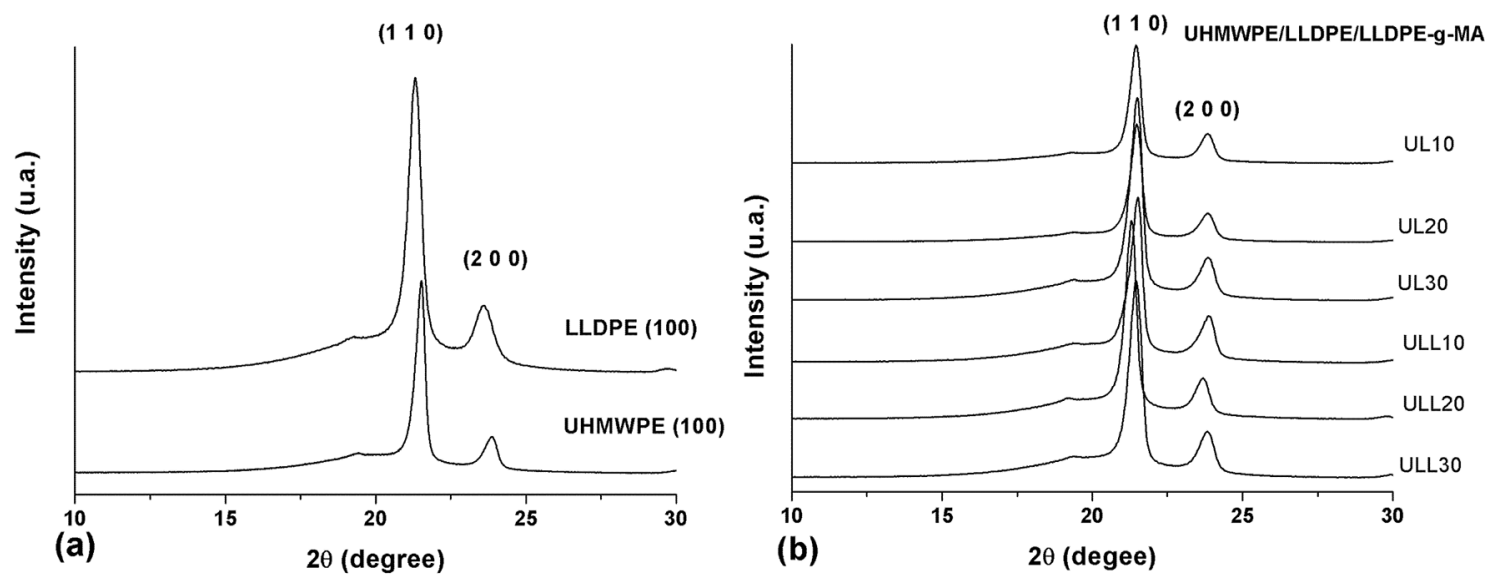

Figure 4. WAXD scans of (a) UHMWPE and LLDPE, and (b) compatibilized and uncompatibilized UHMWPE/LLDPE blends with differents contents of LLDPE.

crystallization. UHMWPE polymer chain may have size 30 times larger than the other polyolefin. Consequently, the degree of crystallinity of UHMWPE is smaller than that of LLDPE. In addition, the crystallinity of the blend increases proportionally with the addition of LLDPE. The addition of compatibilizer agent decreased the crystallinity since it has lower crystallinity than LLDPE ${ }^{20}$. Similarly, increasing the content of LLDPE an increment in the degree of crystallinity was observed for these blends. Similar results on the decrease in crystallite size have already been reported for polyethylene based HDPE/UHMWPE blend system with decrease UHMWPE content ${ }^{9}$. However, it can be observed a decrease in the crystallite size with the addition of LLDPE. The polyethylene presents orthorhombic crystalline and the diffraction profiles are relative to the crystallographic planes (110), (200) and (020). The apparent crystallite size was calculated using the plane $\left(\begin{array}{lll}1 & 1 & 0\end{array}\right)$ that correspond to the diagonal plane a-b. Concerning the intermolecular heterogeneity between UHMWPE and LLDPE (mainly due to the difference in an average molecular weight), in 
Table 3. Values of crystalline parameters for UHMWPE, LLDPE, UL blends and ULL blends from X-ray data.

\begin{tabular}{lcc}
\hline Sample & Crystallinity $(\%)$ & Crystalline size $(\mathrm{nm})$ \\
\hline UHMWPE & 48.7 & 35.7 \\
$(100)$ & 55.8 & 25.3 \\
LLDPE (100) & 57.6 & 30.4 \\
UL10 & 58.4 & 30.2 \\
UL20 & 60.2 & 27.4 \\
UL30 & 54.9 & 30.4 \\
ULL10 & 56.9 & 27.2 \\
ULL20 & 57.0 & 26.8 \\
ULL30 & & \\
\hline
\end{tabular}

the rich domain of one kind of macromolecule, the regular arrangement of the chain segments of the other species might be excluded during crystallization and the crystal size becomes smaller ${ }^{21}$. The addition of compatibilizer agent also influences the crystallite size. It is noted that increasing the content of LLDPE (and consequently the content of LLDPEg-MA) the size of the crystal decreases.

SEM micrographs of neat UHMWPE and the blends are presented in Figure 5. According to SEM images, the fractured surface of UHMWPE (Fig. 5a) presents uniform morphology and a very flat surface, indicating a less ductile behavior due to the high chain size and linear structure. The fractured surface of UL blends (Figures $5 \mathrm{~b}$-d-f) present uniform morphology composed of millions of rod-like structure, and these tiny "rods" are connected with each other. The addition of LLDPE-g-MA modify the interior morphology of UHMWPE, and even voids can be observed (Figures $5 \mathrm{c}-\mathrm{e}-\mathrm{g}$ ). No evidence of a separate LLDPE phase was found; in view of a large number of images that were investigated, the absence of any visible separate LLDPE phase. A similar result was obtained by Jiang et al. ${ }^{22}$, that verified the influence of maleic anhydride-grafted polyethylene in blends of low-density polyethylene (LDPE) with polyamide- 6 (PA6), i.e., the authors verified a good interfacial adhesion between the phases.

The influence of aging on the thermal and mechanical behavior of the blends is an important parameter to understand the effect of weathering on the material. The studied samples were submitted to two different types of aging and correlated with samples without aging (reference samples - referred to as RS). Table 4 shows the values of the Charpy impact strength of the notched samples. It was observed that the UHMWPE does not present total fracture for any type of aging. The reference samples of the blends without the addition of compatibilizer agent (UL) also did not present total fracture for the studied LLDPE contents. However, when submitted to both types of aging it presented total fracture. On the other hand, the addition of LLDPE-g-MA affects greatly the mechanical behavior once all the compatibilized samples presented total fracture.
In order to understand the mechanical behavior of the samples, DSC analyzes were performed on all samples and the results are shown in Table 5. Figure 6a shows water absorption of samples aged in water at $80^{\circ} \mathrm{C}$ for 7 days and Figure $6 \mathrm{~b}$ presents the degree of crystallinity of all samples studied. Only the first heating was evaluated to verify the influence of aging in the degree of crystallinity of the samples.

DSC analysis of the compositions showed that all samples aged in air circulation oven presented an increase in the degree of crystallinity due to the relief of the thermal stresses, resulting from the processing that allowed for the rearrangement of the molecules. The samples submitted to treatment in water also showed an increment in the crystallinity of neat UHMWPE and UL blends, but to a lesser extent, due to the water temperature, which was at $80^{\circ} \mathrm{C}$. No plasticizing behavior was identified for the UL blends due to the hydrophobic nature of the polymer material used. The plasticizing effect decreases the degree of crystallinity since it causes a reduction in the cohesive intermolecular forces along the polymer chains. Similar results on the increase in crystallinity have already been reported for HDPE/LLDPE blend when subjected to these aging ${ }^{23}$.

All samples aged in water showed low water absorption (Figure 6a). Increasing the content of LLDPE in the composition there is a slight increment in the water absorption, however, as the polyolefins are hydrophobic these values did not alter the structure of the polymer blends.

On the other hand, the addition of LLDPE-g-MA alters the degree of crystallinity of the blends when aged in water. The carbonyl groups are able to interact to a greater extent with the absorbed water molecules ${ }^{24}$. Hydrogen bonding between water and the polar polymer has been confirmed by a shift in the carbonyl peaks toward lower wavenumbers in FTIR spectrum, $1720 \mathrm{~cm}^{-1}$ (Figure 7c). One hypothesis is that a semicrystalline polymer with a lower degree of crystallinity, has a higher amount of amorphous phase and the amorphous phase contains a finite amount of hydrophilic sites that become saturated at some critical moisture content. Above this moisture content value, absorbed water molecules have a greater molecular mobility ${ }^{24-25}$. Then, the hydrogen bond interactions between the carbonyl group and water molecules decrease $\mathrm{e}^{25}$, the polymer becomes plasticized and undergoes structural changes which may then affect the mobility and the degree of crystallinity of the blend.

Figure 7 shows FTIR spectra of the compositions studied. The main characteristic peaks of polyethylene are shown in Figure 7a. The region comprising peaks at 2920 and $2850 \mathrm{~cm}^{-1}$ refer to the asymmetric and symmetrical axial deformation of the $-\mathrm{CH}_{2}$. The peaks at 1473 and $1453 \mathrm{~cm}^{-1}$ correspond to the angular deformation of $-\mathrm{CH}$ and the peaks at $716 \mathrm{~cm}^{-1}$ correspond to the symmetrical angular deformation of $-\mathrm{CH}_{2}$ (rocking). In the spectra obtained from the compatibilized blends, the peak at $1720 \mathrm{~cm}^{-1}$ corresponding to the carbonyl groups, characteristic of the maleic anhydride present in the 

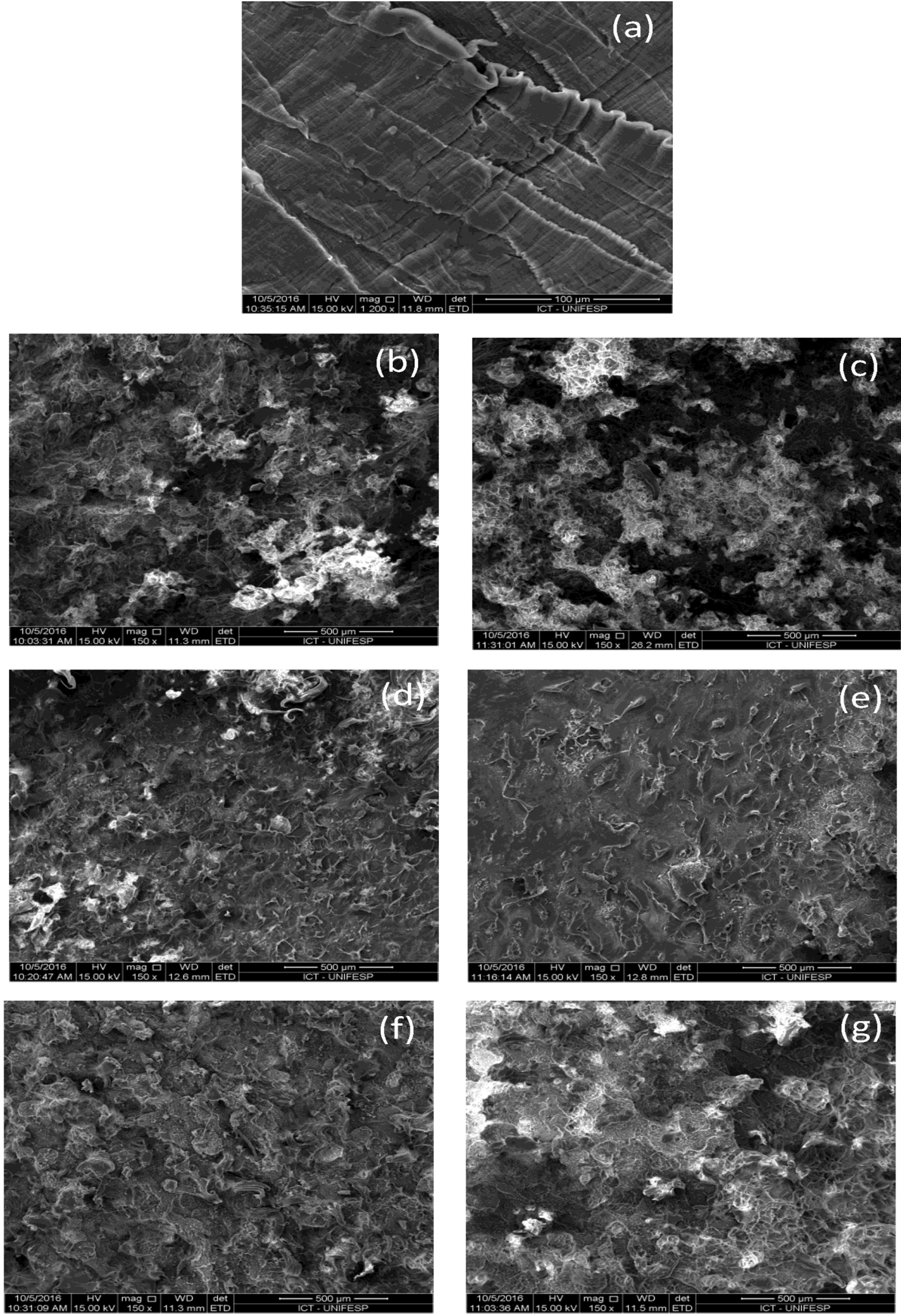

Figure 5. SEM micrographs: (a) UHMWPE (100), (b) UL10, (c) ULL10, (d) UL20, (e) ULL20, (f) UL30 and (g) ULL30. Micrographs with magnification of $150 \mathrm{x}$. 
compatibilizer agent ${ }^{26-27}$. The presence of branching and tertiary carbons in polyolefin chains makes them susceptible to attack by free radicals and oxygen and, therefore, to degradation $^{26}$. Thermo-oxidation of UHMWPE and LLDPE can significantly affect the physicochemical properties of polymers, such as increased crystalline fraction, elastic modulus, and impact properties ${ }^{27}$. It is observed that no thermo-oxidative processes occurred since the exposure time was reduced, so the decrease of the impact resistance

Table 4. Charpy impact strength of the notched reference samples (RS), samples aged in oven at $110 \mathrm{oC}$ for 7 days (AO) and samples aged in water at $80 \mathrm{oC}$ for 7 days (AW).

\begin{tabular}{lccc}
\hline \multirow{2}{*}{ Samples } & \multicolumn{3}{c}{ Charpy Impact Resistance $(\mathrm{J} / \mathrm{m})$} \\
\cline { 2 - 4 } & $\mathrm{RS}$ & $\mathrm{AO}$ & $\mathrm{AW}$ \\
\hline UHMW-PE (100) & $\mathrm{NB} *$ & $\mathrm{NB}$ & $\mathrm{NB}$ \\
UL10 & $\mathrm{NB}$ & $9.0 \pm 0.8$ & $11.5 \pm 0.4$ \\
UL20 & $\mathrm{NB}$ & $2.9 \pm 0.1$ & $4.7 \pm 0,1$ \\
UL30 & $\mathrm{NB}$ & $2.5 \pm 0.1$ & $3.1 \pm 0.1$ \\
ULL10 & $11.4 \pm 0.2$ & $6.8 \pm 0.1$ & $9.2 \pm 0.1$ \\
ULL20 & $6.7 \pm 0.1$ & $1.9 \pm 0.1$ & $6.2 \pm 0.1$ \\
ULL30 & $5.5 \pm 0.1$ & $1.4 \pm 0.1$ & $4.9 \pm 0.1$ \\
\hline
\end{tabular}

*NB - Not break to samples aged in the oven is due to the increase in the degree of crystallinity.

For samples aged in the oven for 7 days, identified as $\mathrm{AO}$, a decrease in impact strength is observed. The increase in the degree of crystallinity increases the stiffness of the material and consequently reduces the impact resistance. By increasing the content of LLDPE in the compositions, lower values of impact resistance are observed.

\section{Conclusions}

UHMWPE/LLDPE blends with and without the addition of LLDPE-g-MA and with different LLDPE contents were prepared by melt blending. The addition of the second phase (LLDPE), with low viscosity in the molten state, aided the mixing process. The UHMWPE/LLDPE blends presented miscibility and only one crystallization temperature and one melting temperature peaks were observed indicating the existence of only one type of crystal species. The degree of crystallinity increased with the content of LLDPE. On the other hand, the addition of compatibilizer agent in the systems modifies the crystallinity. Increasing LLDPE content in the composition shows up a lower temperature shoulder peak and a higher temperature peak a shoulder in

Table 5. Melting temperature ( $\mathrm{Tm})$ and degree of crystallinity $(\mathrm{Xc})$ of the samples aged in oven at $110^{\circ} \mathrm{C}$ for 7 days (AO), samples aged in water at $80^{\circ} \mathrm{C}$ for 7 days (AW) and reference samples (RF).

\begin{tabular}{lccccccccc}
\hline \multirow{2}{*}{ Compositions } & \multicolumn{3}{c}{ Reference Samples $(\mathrm{RS})$} & \multicolumn{3}{c}{ Samples aged in oven $(\mathrm{AO})$} & \multicolumn{3}{c}{ Samples aged in water $(\mathrm{AW})$} \\
\cline { 2 - 9 } & $\mathrm{Tm}_{1}\left({ }^{\circ} \mathrm{C}\right)$ & $\Delta \mathrm{Hm}_{1}(\mathrm{~J} / \mathrm{g})$ & $\mathrm{Xc}_{1}(\%)$ & $\mathrm{Tm}_{1}\left({ }^{\circ} \mathrm{C}\right)$ & $\Delta \mathrm{Hm}_{1}(\mathrm{~J} / \mathrm{g})$ & $\mathrm{Xc}_{1}(\%)$ & $\mathrm{Tm}_{1}\left({ }^{\circ} \mathrm{C}\right)$ & $\Delta \mathrm{Hm}_{1}(\mathrm{~J} / \mathrm{g})$ & $\mathrm{Xc}(\%)$ \\
\hline UHMW-PE & 135 & 113.3 & $\mathbf{3 9 . 6}$ & 147.6 & 196.1 & $\mathbf{6 8 . 5}$ & 139.9 & 125.8 & $\mathbf{4 4 . 0}$ \\
$(100)$ & 133 & 133.4 & $\mathbf{4 9 . 1}$ & 142.7 & 172.6 & $\mathbf{6 3 . 4}$ & 139.9 & 141.4 & $\mathbf{5 2 . 0}$ \\
UL10 & 132 & 140.4 & $\mathbf{5 4 . 6}$ & 143.0 & 144.6 & $\mathbf{5 6 . 2}$ & 136.2 & 141.7 & $\mathbf{5 5 . 1}$ \\
UL20 & 132 & 117.5 & $\mathbf{4 8 . 4}$ & 140.0 & 147.0 & $\mathbf{6 0 . 6}$ & 135.7 & 141.2 & $\mathbf{5 8 . 2}$ \\
UL30 & 133 & 124.3 & $\mathbf{4 7 . 0}$ & 140.1 & 144.7 & $\mathbf{5 4 . 7}$ & 139.1 & 123.8 & $\mathbf{4 6 . 4}$ \\
ULL10 & 132 & 126.0 & $\mathbf{5 2 . 0}$ & 146.2 & 128.8 & $\mathbf{5 3 . 1}$ & 134.1 & 111.1 & $\mathbf{4 5 . 8}$ \\
ULL20 & 132 & 129.3 & $\mathbf{5 8 . 6}$ & 142.5 & 142.5 & $\mathbf{6 4 . 6}$ & 137.2 & 126.8 & $\mathbf{5 7 . 5}$ \\
ULL30 & & & & & & & &
\end{tabular}

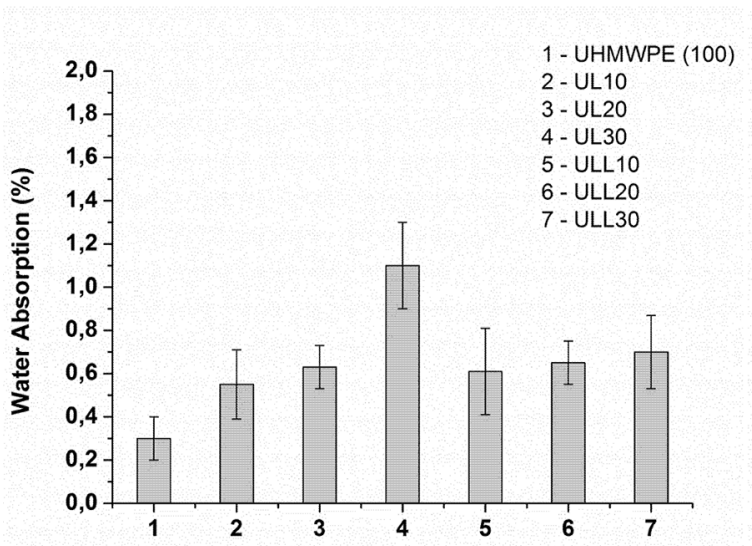

(a) Compositions

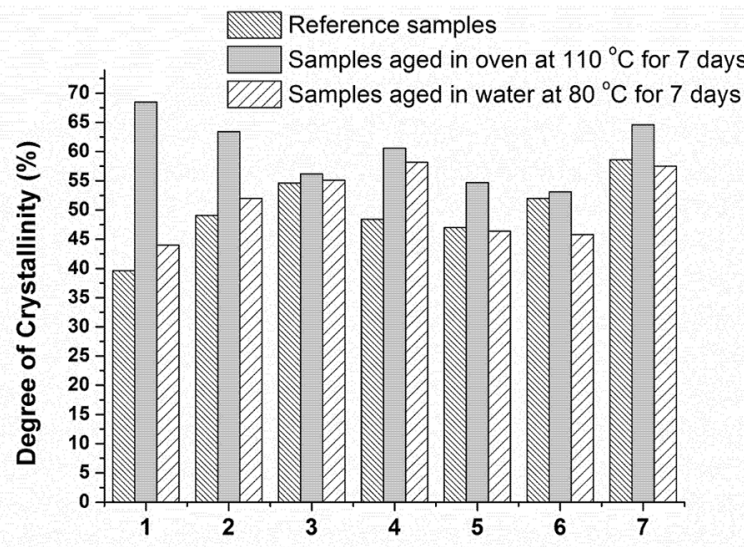

(b)

Compositions

Figure 6. (a) Water absorption of samples aged in water at $80^{\circ} \mathrm{C}$ for 7 days and (b) Degree of crystallinity of reference samples, samples aged in oven at $100^{\circ} \mathrm{C}$ for 7 days and samples aged in water at $80^{\circ} \mathrm{C}$ for 7 days. 

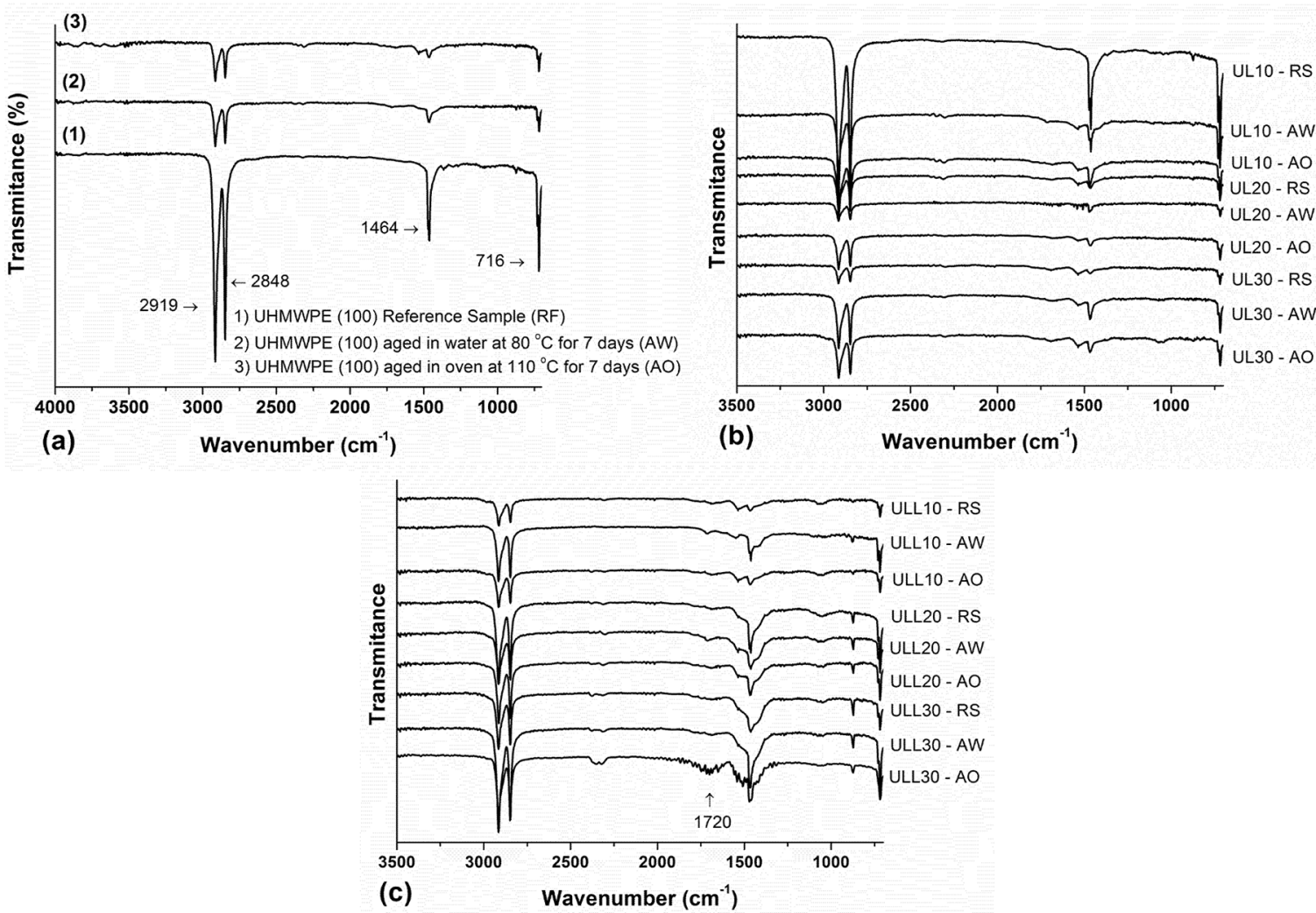

Figure 7. FT-IR curves: (a) UHMWPE (100) reference sample (RF), aged in oven at $100^{\circ} \mathrm{C}$ for 7 days (AO) and aged in water at $80^{\circ} \mathrm{C}$ for 7 days (AW), (b) UHMWPE/LLDPE blends with different contents of LLDPE and (c) UHMWPE/LLDPE/LLDPE-g-MA blends with different contents of LLDPE.

the crystallization curve. The addition of compatibilizer agent also decreases the crystallite size. Non-compatibilized blends have excellent impact resistance properties. However, the addition of compatibilizer agent weakens the polymer blends. UHMWPE/LLDPE blends were greatly affected by thermal aging and water aging. Thermal aging lead to an increment in the degree of crystallinity of the composition, i.e, increase in stiffness and decrease in impact strength. Aging in water mainly affects compatibilized blends due to interactions between the polar group and water, causing a plasticizing effect and decreasing the degree of crystallinity.

\section{Acknowledgements}

The authors would like to thank FAPESP (2014/04900-9 and 2016/19978-9) for the financial support.

\section{References}

1. Lu SH, Liang GZ, Zhou ZW, Li F. Structure and properties of UHMWPE fiber/carbon fiber hybrid composites. Journal of Applied Polymer Science. 2006;101(3):1880-1884.

2. Huang W, Wang Y, Xia YM. Statistical dynamic tensile strength of UHMWPE-fibers. Polymer. 2004;45(11):3729-3734.
3. Khasraghi SS, Rezaei M. Preparation and characterization of UHMWPE/HDPE/MWCNT melt-blended nanocomposites. Journal of Thermoplastic Composite Materials. 2015;28(3):305326.

4. Chen Y, Nie X, Zou H, Liang M, Liu P. Structure and tensile properties change of LDPE/UHMWPE blends via solid state shear milling. Journal of Applied Polymer Science. 2013;130(4):24872493.

5. Kurtz SM, Muratoglu OK, Evans M, Edidin AA. Advances in the processing, sterilization, and crosslinking of ultra-high molecular weight polyethylene for total joint arthroplasty. Biomaterials. 1999;20(18):1659-1688.

6. He S, He H, Li YC, Wang DQ. Effects of maleic anhydride grafted polyethylene on rheological, thermal, and mechanical properties of ultra high molecular weight polyethylene/ poly(ethylene glycol) blends. Journal of Applied Polymer Science. 2015;132(43):42701.

7. Ronca S, Forte G, Ailianou A, Kornfield JA, Rastogi S. Direct Route to Colloidal UHMWPE by Including LLDPE in Solution during Homogeneous Polymerization of Ethylene. ACS Macro Letters. 2012;1(9):1116-1120.

8. Kurtz SM. The UHMWPE Handbook. Ultra-High Molecular Weight Polyethylene in Total Joint Replacement. San Diego: Academic Press; 2004. 
9. Jaggi HS, Satapathy BK, Ray AR. Viscoelastic properties correlations to morphological and mechanical response of HDPE/UHMWPE blends. Journal of Polymer Research. 2014;21(8):482.

10. Wu YC, Cui YH, Jin HL, Ning CC. Study on the preparation and thermal shrinkage properties of nano-SiO2/UHMWPE/ HDPE blend microporous membranes. Journal of Applied Polymer Science. 2015;132(3):41321.

11. Chen Y, Li Y, Zou H, Liang M. Effect of solid-state shear milling on structure and properties of HDPE/UHMWPE blends. Journal of Applied Polymer Science. 2014;131(4):39916.

12. Shen H, He L, Fan C, Xie B, Yang W, Yang M. Improving the integration of HDPE/UHMWPE blends by high temperature melting and subsequent shear. Materials Letters. 2015;138:247250 .

13. Shen H, He L, Fan C, Xie B, Yang W, Yang M. Effective dissolution of UHMWPE in HDPE improved by high temperature melting and subsequent shear. Polymer Engineering and Science. 2015;55(2):270-276.

14. Boscolleto AB, Franco R, Scapin M, Tavan M. An investigation on rheological and impact behaviour of high density and ultra high molecular weight polyethylene mixtures. European Polymer Journal. 1997;33(1):97-105.

15. Kyu T, Vadhar P. Cocrystallization and miscibility studies of blends of ultrahigh molecular weight polyethylene with conventional polyethylenes. Journal of Applied Polymer Science. 1986;32(6):5575-5584.

16. Chen Y, Zou H, Cao Y, Liang M. Melt miscibility of HDPE/ UHMWPE, LDPE/UHMWPE, and LLDPE/UHMWPE blends detected by dynamic rheometer. Polymer Science Series A. 2014;56(5):630-639.

17. Harrats C, Thomas S, Groeninckx G. Micro- and Nanostructured Polymer Blend Systems: Phase Morphology and Interfaces. Boca Raton: CRC Press; 2005.
18. Utracki LA. Commercial Polymer Blends. New York: Springer; 1998.

19. Passador FR, Ruvolo-Filho AC, Pessan LA. Structural, thermal, and gas transport properties of HDPE/LLDPE blend-based nanocomposites using a mixture of HDPE-g-MA and LLDPEg-MA as compatibilizer. Polymer Engineering and Science. 2016;56(7):765-775

20. Wu T, Li Y, Wu G. Crystalline structure and phase structure of mLLDPE/LDPE blends. Polymer. 2005;46(10):3472-3480.

21. Jothi KJ, Santhoskumar AU, Amanulla S, Palanivelu KJ. Thermally Sprayable Anti-Corrosion Marine Coatings Based on MAH-g-LDPE/UHMWPE Nnanocomposites. Journal of Thermal Spray Technology. 2014;23(8):1413-1424.

22. Jiang C, Filippi S, Magagnini P. Reactive compatibilizer precursors for LDPE/PA6 blends. II: maleic anhydride grafted polyethylenes. Polymer. 2003;44(8):2411-2422.

23. Passador FR, Travain DR, Backes EH, Ruvolo Filho AC, Pessan LA. Nanocompósitos de blendas HDPE/LLDPE e OMMT - Parte II: avaliação das propriedades térmica, óticas e de transporte a gases. Polímeros. 2013;23(6):748-757.

24. Shah N, Sandhu H, Choi DS, Chokshi H, Malick AW, eds. Amorphous Solid Dispersions: Theory and Practice. New York: Springer; 2014.

25. Wang W, Ye S. Molecular interactions of organic molecules at the air/water interface investigated by sum frequency generation vibrational spectroscopy. Physical Chemistry Chemical Physics. 2017;19(6):4488-4493.

26. Gulmine JV, Janissek PR, Heise HM, Akcelrud L. Polyethylene characterization by FTIR. Polymer Testing. 2002;21(5):557563.

27. Pagès $P$, Carrasco F, Saurina J, Colom X. FTIR and DSC study of HDPE structural changes and mechanical properties variation when exposed to weathering aging during canadian winter. Journal of Applied Polymer Science. 1996;60(2):153-159. 